\title{
A Transformação Curricular e a Escolha da Especialidade Médica
}

\author{
The Transformation to the Medical \\ Curriculum and Choosing a Medical \\ Specialization
}

\author{
José Roberto Bittencourt Costa ${ }^{I}$ \\ Valéria Ferreira Romano ${ }^{I I}$ \\ Rosane Rodrigues Costa ${ }^{I I I}$ \\ Andréia Patrícia Gomes ${ }^{I V}$ \\ Luiz Anastácio Alves ${ }^{I}$ \\ Rodrigo Siqueira-BatistaV
}

\section{PALAVRAS-CHAVE \\ - Escolha da Profissão; \\ - Estudantes de Medicina; \\ - Saúde da Família; \\ - Aprendizagem Baseada em Problemas; \\ - Educação Médica.}

\section{KEYWORDS}

- Choice of Specialization;

- Medical Students;

- Family Health;

- Problem-Based Learning;

- Medical Education.

Recebido em: 08/08/2013

Aprovado em: 24/03/2014

REVISTA BRASILEIRA DE EDUCAÇ̃̃o MÉDICA

4738 (1): 47-58; 2014

\begin{abstract}
RESUMO
A reforma curricular implantada em 2005 no curso de graduação em Medicina do Centro Universitário Serra dos Órgãos (Unifeso) com a utilização das metodologias ativas de ensino-aprendizagem, no caso a aprendizagem baseada em problemas (ABP), e com a passagem pela Unidade Básica de Saúde da Família (UBSF) desde os primeiros períodos pode influenciar a trajetória de formação profissional de seu estudante? Para responder a esta questão — objetivo deste estudo —, procedeu-se a uma pesquisa qualitativa com os discentes matriculados no quinto período do curso, por meio de entrevistas, as quais foram categorizadas e analisadas. Os resultados evidenciaram significativa receptividade ao novo modelo curricular, pelo entendimento de que este é capaz de suscitar novas reflexões dirigidas à futura prática do estudante, e, igualmente, ao conceito de saúde e ao processo de adoecimento. Verificou-se, ainda, que a opção precoce por uma especialidade, expressa pela maior parte dos entrevistados, não foi alterada sob o novo currículo e que a formação do médico como generalista ou médico de família é ainda pouco valorizada.
\end{abstract}

\section{ABSTRACT}

This paper asks whether the curriculum change implemented in 2005 to the Centro Universitário Serra dos Órgãos (Unifeso) Undergraduate Medical Course may influence the course of its students' vocational training, through its active teaching and learning methodologies, such as problem-based learning $(P B L)$ and the students' passage through the Primary Care Unit (PCU) in the early years of the course. To answer this objective question, qualitative research was carried out on medical students in the fifth semester, by means of interviews which were categorized and later analyzed. The results showed significant receptivity to the new curriculum model, due to the understanding that such a model is able to inspire new reflections on future student practice and also on the concept of health and the process taken by illnesses. The study also showed that the early option to choose a particular specialization - taken up by the majority of respondents - had not changed under the new curriculum and that the training of medical practitioners or family physicians is still poorly regarded.

\footnotetext{
I Fundação Oswaldo Cruz, Rio de Janeiro, RJ, Brasil.

${ }^{\text {II } U n i v e r s i d a d e ~ F e d e r a l ~ d o ~ R i o ~ d e ~ J a n e i r o, ~ R i o ~ d e ~ J a n e i r o, ~ R J, ~ B r a s i l . ~}$

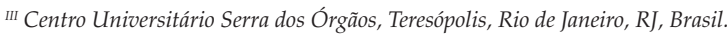

${ }^{\text {IV }}$ Universidade Federal de Viçosa, Minas Gerais, MG, Brasil.

${ }^{V}$ Universidade Federal de Viçosa, Minas Gerais, MG; Universidade Federal do Rio de Janeiro, Rio de Janeiro, RJ; Brasil.
} 


\section{INTRODUÇÃO}

A formação científica do médico, quando centrada na esfera dos fenômenos meramente biológicos, torna a contextualização das dimensões subjetivas e a compreensão dos determinantes sociais e ecológicos do processo saúde-doença ${ }^{1-4}$ tarefa bastante inglória, se não missão praticamente impossível. Como exemplo, Giovanni Berlinguer ${ }^{5}$, médico e notável pesquisador, assinalava a complexidade de conceituar "a doença" — titulo dado ao seu livro - , na medida em que lhe parecia não haver nenhuma definição suficientemente precisa para uma adequada caracterização. De fato, como refere Nogueira ${ }^{6}$, o atual modelo de formação médica - o qual desloca a experiência clinica e a observação da vida para o olhar anatomoclínico, ordenado então pela morte - tem se mostrado limitado e inadequado para responder às complexas demandas de saúde do ser humano.

Ademais, a falta de integração do processo de aprendizagem aos serviços de saúde e de melhor parceria entre as universidades e setores da sociedade civil e comunidades sem a incorporação de uma visão de integralidade tem colaborado para a inadequação do atual modelo de educação médica às demandas sociais e, ainda, de forma mais categórica: a inadequação da formação médica para atuação no Sistema Único de Saúde (SUS) ${ }^{6,7}$.

Diante da percepção da inadequação do atual modelo do ensino de Medicina apontada acima, que tipo de influências poderiam advir na trajetória de formação profissional do estudante de Medicina — ou até mesmo antes de vir a ser — sob o modelo biomédico reducionista e de seus processos de produção do conhecimento e de prática profissional?

Em um estudo efetuado com base na realização de entrevistas com 40 médicos renomados - reconhecidos entre os pares e a sociedade civil -, de diversas especialidades na cidade de São Paulo, Fiore e Yazigi ${ }^{8}$ referem que a formação da identidade médica e de sua prática - notadamente suas percepções e comportamento - é influenciada pelo estrato social e econômico de origem de cada indivíduo e que a escolha da profissão e da especialidade pode estar sujeita a estratégias familiares de ascensão e de manutenção do poder. Em outra investigação relevante - realizada com 202 alunos $\left(\right.$ do $1^{\circ}, 3^{\circ}$ e $5^{\circ}$ ano), além de 60 egressos de uma escola médica no interior do Estado do Rio de Janeiro -, Cabral Filho e Ribeiro ${ }^{9}$ apontam importantes influências na trajetória de formação médica sob a ótica reducionista. A assustadora "escolha precoce" de uma especialidade médica é regularmente aceita e até estimulada por muitas instituições de ensino. A existência de "pseudoespecialistas" - enquanto ainda estudantes de Medicina já desinteressados por áreas básicas consideradas essenciais, como
Pediatria, Clinica Médica e Ginecologia - é frequentemente observada.

Diversos fatores levariam à escolha de (sub)especialidades de forma precoce, com destaque para os avanços tecnológicos e a influência das forças de mercado e do seu monopólio do saber com o exercício da prática profissional especializada - contextualizada no complexo médico industrial (CMI) instalado no século $X X$-, estimulado pelas ideias (neo)liberais voltadas mais para a atenção individual. Ademais, destaque-se a preeminência da ideologia dominante na classe médica - por vezes perpetuada na própria família por parentes também médicos, como pais e irmãos -, que reconhece nas (sub)especialidades que incorporem maior carga tecnológica - como Cirurgia, Oftalmologia, Dermatologia e Oncologia - a possibilidade de obtenção de maior prestigio financeiro e social, em detrimento das especialidades mais ligadas à saúde coletiva e com menor carga tecnológica, como Pediatria, Doenças Infecciosas e Saúde Coletiva, as quais potencialmente trariam menor retorno financeiro e reputação social ${ }^{8,9}$.

Desta feita, compreende-se que o trabalho médico também não poderia ser dissociado da complexa trajetória histórica que produziu e acumulou saberes e práticas próprias, inscritas em um contexto sociopolítico, notoriamente aquele representado pela acumulação capitalista e seu avanço biotecnocientífico na era pós-industrial. Neste arranjo, a "especialização" torna-se uma ótima resposta para as expectativas da sociedade contemporânea ${ }^{10}$, de modo que a adesão precoce à especialidade pelo ainda então estudante de Medicina acabaria não só por estimular e justificar a futura segmentação do trabalho médico, como, também, provocar a perda do raciocínio clínico - semiológico - e da percepção da globalidade que deveria ser inerente à formação do generalista ${ }^{9}$.

Cabe, pois, indagar: como as escolas médicas, criadas para formar profissionais para a sociedade brasileira, respondem atualmente às demandas menos centradas em doenças e mais focadas no cuidado e nas genuínas necessidades de saúde da população? Que estratégias políticas e pedagógicas poderiam ser utilizadas para lidar com o pressuposto da integralidade do cuidado e para minimizar a possível pressão para a escolha precoce de uma especialidade pelos estudantes?

Tais indagações levam, inevitavelmente, às Diretrizes Curriculares Nacionais do Curso de Graduação em Medicina (DCN) e aos programas governamentais de estímulo às mudanças curriculares - mormente aqueles dirigidos às escolas médicas - lançados nos últimos dez anos. Através de uma articulação envolvendo os ministérios da Educação e da Saúde, foram criados (1) o Programa de Incentivos a Mudanças Curriculares em Medicina (Promed, 2002); (2) o Programa 
Nacional de Reorientação da Formação Profissional em Saúde (Pró-Saúde, 2005); e, mais recentemente, (3) o Programa de Educação pelo Trabalho para a Saúde (PET-Saúde, 2010). Assim, houve estímulo para melhor articulação entre as instituições de formação e o sistema de saúde e a real possibilidade de modificação desta condição $0^{10-13}$.

Dentre as principais estratégias pedagógicas defendidas por tais iniciativas podem ser ressaltadas duas: a diversificação dos cenários de ensino-aprendizagem — os quais devem ser vividos pelos estudantes desde o primeiro período - e a utilização de metodologias ativas de ensino-aprendizagem (MAEA).

Em relação à primeira estratégia, os novos cenários podem figurar como eixo educacional para a aprendizagem de uma medicina mais próxima das pessoas. Segundo as DCN, o SUS - através de suas unidades de saúde - deve receber os graduandos logo nas primeiras séries do curso, não somente como meros observadores, mas como partícipes ativos - de acordo com seu nível de conhecimento - das mais díspares circunstâncias, tais como aquelas atinentes à relação usuário / profissional, comunicação diagnóstica e abordagem terapêutica, aspectos estes regidos por variantes sociais, econômicas, culturais e locorregionais ${ }^{14,15}$. Neste sentido, pode-se citar o oportuno estudo etnográfico de Nogueira ${ }^{6}$ a partir da experiência da reforma curricular da Faculdade de Medicina da Universidade Federal Fluminense (UFF), em Niterói, com a disciplina Trabalho de Campo Supervisionado, na qual os alunos são inseridos em cenários da vida real, como Unidades Básicas de Saúde, além de cenários sociais e de organizações não governamentais. Segundo a autora, a construção de um novo olhar - mais ampliado - sobre o sujeito e sobre a produção de cuidados na Atenção Básica é factível e pode estar coerente com um projeto político e ético-humanista que reconhece no SUS um catalisador das transformações requeridas na educação médica. Portanto, a Estratégia Saúde da Família (ESF) - com a inserção de alunos em Unidades Básicas de Saúde da Família (UBSF) desde os primeiros períodos dos cursos de graduação em Medicina - pode se traduzir como cenário extremamente relevante para o ensino da Medicina, na medida em que é considerada o modelo de reorganização da Atenção Primária à Saúde (APS) — ou da Atenção Básica à Saúde — no âmbito do SUS ${ }^{16}$.

No que diz respeito à segunda estratégia, o uso das MAEA - mais especificamente a Aprendizagem Baseada em Problemas $(\mathrm{ABP})$ - , esta vem se tornando extremamente importante, uma vez que situa o estudante no centro do processo de ensino-aprendizagem, como protagonista de seu próprio processo de formação ${ }^{17,18}$. Toralles-Pereira et al. chamam a atenção para o papel humanizador que o ensino dos profissionais de saúde deve assumir, ressaltando a importância das estratégias de MAEA neste processo:

O processo de mudança da educação traz inúmeros desafios, entre os quais romper com estruturas cristalizadas e modelos de ensino tradicional e formar profissionais de saúde com competências que lhes permitam recuperar a dimensão essencial do cuidado: a relação entre humanos.[... $]^{19}$ (p. 780-781)

No entanto, apesar da existência destes programas governamentais de estímulo às mudanças curriculares e das DCN, as discussões e reflexões sobre a capacidade de formar médicos - e outros profissionais de saúde - capazes de "cuidar do florescer da vida", como referido por Vasconcelos et al. ${ }^{20}$, trazem à tona os impasses recorrentes que ainda permeiam o ensino médico brasileiro, notoriamente aqueles relacionados à subjetividade, aos sentimentos, às emoções, à espiritualidade e à coletividade em meio à percepção reducionista das ciências da saúde. O "cuidar do outro", "o cuidar de si", "o aprender juntos", "o comprometer-se politicamente" são exemplos de termos provenientes de práticas de extensão universitária orientadas pela educação popular - e do forte contato com a miséria e do encontro (trágico) com a morte - , mas ainda frequentemente distantes dos currículos de muitas escolas médicas $^{21,22}$

Tais aspectos podem ser considerados marcos na compreensão do atual olhar médico, o qual, no pano de fundo apresentado, pouco a pouco naturalizaria uma prática frequentemente opressora, permeada pelo ensino autoritário e pelo distanciamento da vida ${ }^{20}$. Por outro lado, a "problematização da vida" e o estudo cada vez maior das "ciências da vida" têm se tornado temas recorrentes - sobretudo na educação médica - , passíveis, ainda, de constantes redefinições e transformações ${ }^{23}$. Há, sim, jardins de inverno nas universidades aparentemente frias onde se formam os profissionais de saúde, como afirmam Vasconcelos et al. ${ }^{20}$, a partir dos depoimentos e vivências de médicos, enfermeiros, fisioterapeutas e estudantes de graduação destes cursos, retratados no livro Perplexidade na Universidade. São relatos dotados de espírito crítico e que expressam a resistência à naturalização das condições discutidas acima e de sua (en)culturação no âmbito das escolas médicas. Sobretudo, são personagens que demonstram indignação e inconformidade com o atual modelo reducionista de ensino em saúde, o qual desconsidera a subjetividade do processo de adoecer ainda recorrente nas universidades brasileiras ${ }^{20}$.

É precisamente sobre esses "jardins de inverno" que o presente estudo se debruça, ao abordar a trajetória de formação 
médica sob um novo modelo curricular, como o que foi promovido no Centro Universitário Serra dos Órgãos (Unifeso). Seriam os referidos "jardins da reforma curricular" capazes de se legitimarem como possíveis respiradouros para a retomada de conceitos adormecidos - e tão fundamentais à prática médica - , como "integralidade e humanização" e ultrapassar o discurso da "necessária escolha precoce de uma especialidade médica por seus estudantes"?

O Unifeso, situado em Teresópolis (RJ), em concordância com as premissas de transformação do ensino de Medicina já discutidas, definiu em 2005 um novo modelo curricular centrado nas $\mathrm{MAEA}$ - no caso a $\mathrm{ABP}$ - e na inserção precoce em cenários vivos de ensino-aprendizagem — UBSF — a partir do primeiro período do curso ${ }^{24,25}$. Com base nessas conjecturas, objetivou-se neste trabalho analisar as possíveis influências existentes na trajetória de formação profissional do graduando em Medicina do quinto período a partir da referida mudança curricular, como explicitado na Figura 1.

\section{FIGURA 1}

Diagrama representativo das influências presentes na trajetória de formação profissional do estudante de Medicina

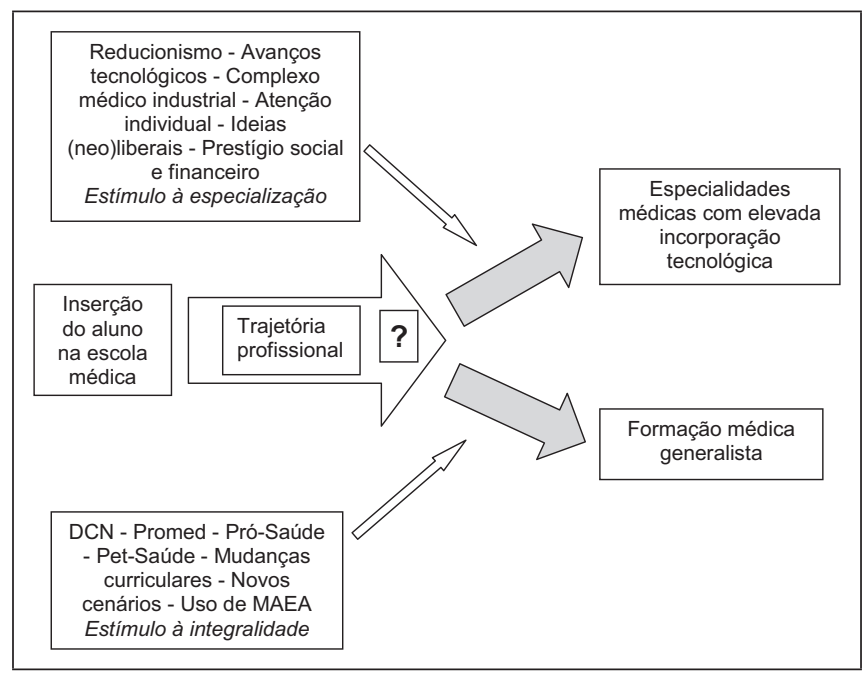

\section{MÉTODOS}

A pesquisa, de natureza qualitativa, foi realizada no Unifeso, situada no município de Teresópolis, Rio de Janeiro, com alunos matriculados regularmente no quinto período do curso de graduação em Medicina. A escolha desse grupo de alunos foi motivada tanto por já terem apresentado uma boa experiência nos cenários das UBSF, onde já haviam cursado quatro períodos, como também pelo uso da ABP. Optou-se por estabelecer uma amostra definida pelos critérios propostos por Minayo ${ }^{26}$, ao afirmar que na pesquisa qualitativa em saúde a amostra deve responder às normas de validade (representatividade, exaustividade e pertinência) e que, no caso da análise temática - estratégia utilizada neste estudo e explicitada mais adiante -, esta utiliza a "contagem de frequência das unidades de significação como definitórias do discurso", condição esta que foi seguida na investigação.

Em relação ao caráter da "contagem" referido acima por Minayo et $a l .{ }^{26}$, apresentam um interessante estudo a respeito do "tamanho da amostra" em pesquisa qualitativa. Em Amostragem em pesquisas qualitativas: proposta de procedimentos para constatar saturação teórica, os referidos autores sugerem - a título de transparência quanto ao critério de amostragem e de confiabilidade em relação aos dados coletados e analisados em pesquisa qualitativa - oito passos procedimentais para constatação da saturação teórica. Destacam que os elementos iniciais e intermediários - passos de 1 a 5 - representariam a disponibilização dos dados brutos, a compilação de temas, enunciados e a criação de categorias; já nos três últimos aspectos seria possível verificar a "saturação de respostas semelhantes ou iguais" a partir da percepção dos enunciados recorrentes quando alocados, por exemplo, numa tabela, na qual, pela soma dos temas ou enunciados de cada entrevista realizada, seria constatada a saturação das categorias apresentadas e, portanto, a interrupção da captação de novas entrevistas. Entretanto, referem os autores que a recorrência não é por si só o aspecto mais importante, pois "apenas revela o que teria sido mais comumente enunciado em uma amostra intencional". Desta perspectiva, enunciados ou temas que surgiram uma única vez devem também ser analisados, pois podem dizer respeito a "produtos de visões mais abrangentes ou profundas de um participante em particular", aspecto este que também foi considerado neste estudo.

Com efeito, o número final de alunos - tendo em vista os critérios assinalados acima - foi de 29 estudantes entrevistados, dentre todos os matriculados regularmente no quinto período ( $\mathrm{n}=72$ discentes) - ou seja, aproximadamente $40 \%$ destes. As entrevistas foram realizadas no Campus Sede do Unifeso, após a assinatura do Termo de Consentimento Livre e Esclarecido (TCLE). A investigação foi realizada a partir da aprovação do protocolo de pesquisa pelo Comitê de Ética em Pesquisa do Unifeso (Memorando de Aprovação nº 166/08). O protocolo está em consonância com o estabelecido na Resolução 196/96 do Conselho Nacional de Saúde e suas complementares $^{28}$.

As entrevistas - com 15 estudantes do sexo masculino e 14 do sexo feminino - foram realizadas sem a utilização de estratégias específicas para gerar uma amostra aleatória, 
senão a partir da abordagem dos alunos nas salas de aulas. As idades variaram entre 20 e 27 anos, sendo o predomínio entre 20 e 23 anos. O ponto de partida foi a seguinte pergunta aberta: O novo modelo curricular adotado pelo Unifeso no curso de Medicina está tendo alguma influência na sua trajetória profissional?

É importante ressaltar que a questão formulada acima, ao referenciar "o novo modelo curricular adotado", contempla dois aspectos indissociáveis abordados neste estudo e já enunciados - inserção na UBSF desde o primeiro período e uso da $\mathrm{ABP}$ - , uma vez que o novo currículo do curso de graduação em Medicina do Unifeso os adotou em conjunto. A partir destas duas condições analisou-se a percepção da receptividade e da influência que poderia haver na trajetória profissional dos graduandos sob o novo modelo curricular.

Inicialmente, foram realizadas oito entrevistas - a título de estudo piloto do roteiro de entrevista. Assim, verificou-se o grau de compreensão da questão efetuada pelo entrevistador, bem como sua habilidade em não induzir ou direcionar respostas. Os dados obtidos foram apreciados através do processo de Análise Temática, o qual, segundo Minayo ${ }^{26}$, é o que melhor se adapta à investigação qualitativa do material sobre saúde. Foram seguidas as três etapas operacionais da Análise Temática: (1) pré-análise, decomposta em leitura flutuante, constituição do corpus e formulação de hipóteses e objetivos com base nas respostas dos entrevistados; (2) exploração do material; (3) tratamento dos resultados obtidos e interpretação. Na segunda fase foi incluída a análise das questões em categorias ${ }^{26}$.

Bardin $^{29}$ define que as categorias seriam rubricas - ou classes reunidas - a partir de um grupo de elementos definidos também como unidades de registro - sob um título genérico - e agrupadas em razão de características comuns desses elementos. Refere, ainda, três elementos essenciais para compô-las: (i) pertinência, ou seja, possuir uma ideia de adequação ótima, refletindo as intenções da pesquisa; (ii) objetividade $e$ fidelidade, procurando a codificação de uma mesma maneira, evitando a "subjetividade e a variação de juízos" na escolha de categorias; e, por fim, (iii) produtividade, na qual "um conjunto de categorias é considerado produtivo se fornece resultados férteis: férteis em índices de inferências, em hipóteses novas e em dados exatos". Procurou-se seguir tais princípios na análise das respostas dos entrevistados.

O critério adotado de categorização desta pesquisa foi o semântico, ou seja, procurou-se criar categorias por temas de acordo com as respostas fornecidas ${ }^{28}$. A análise geral - no bojo da investigação - levou em consideração a frequência absoluta das expressões referidas para compor cada categoria e a combinação do número destas expressões pelos estudantes, analisando, assim, o número de alunos entrevistados e suas categorias referidas em frequência relativa - porcentagem. Essas categorias - como já definido - foram criadas a partir de expressões, termos ou ideias citados nas respostas, sendo divididas em dois grupos de categorias. O primeiro grupo inclui aquelas classificadas como "potencialmente suscitadoras de influenciar a trajetória profissional do graduando de Medicina", uma vez que representam algum grau de reflexão ou questionamento para a transformação, modificação ou melhor percepção de sua trajetória profissional; o segundo grupo como "potencialmente não suscitadoras de influenciar a trajetória profissional do graduando de Medicina", já que parecem representar pouco ou nenhum grau para modificação desta trajetória, embora não se negue, a rigor, que esta condição não possa ainda suscitar reflexões ou questionamentos. Para efeito de síntese, foram definidas como "categorias suscitadoras" e "categorias não suscitadoras".

Optamos ainda por problematizar cada uma das categorias apresentadas nos dois grupos a partir das expressões apresentadas nas entrevistas com base em sua acepção verbal — verbo problematizar —, tendo como significado "oferecer a forma de um problema". Este foi um artifício utilizado pelos autores para desnaturalizar e desconstruir expressões tidas como "certas ou erradas" ou "verdadeiras ou falsas" obtidas nestas entrevistas. Tal artifício permite repensar o que seria normativo, questionar, de alguma forma, de onde surgiria essa normatividade, relativizando conceitos e possíveis significados de seus discursos.

Foram identificadas quatro categorias como suscitadoras de influenciar a trajetória profissional do graduando de Medicina:

- Humanização;

- Estímulo ao estudo;

- Segurança com o paciente;

- Influência presente (principalmente na especialidade).

Esta última categoria expressa predominantemente - e, portanto, não somente - as reflexões a respeito de uma possível influência sobre a escolha (ou ainda não) de uma especialidade, tendo sido desmembrada em duas para melhor identificá-la: lidade",

- "influenciando, mas sem definição ainda da futura especia-

— "influenciando, mas com a especialidade já definida" (modifica a maneira de ver a especialidade já definida, sem mudá-la).

Somente uma categoria foi contemplada como "não suscitadora de influenciar a trajetória profissional do graduando de Medicina", definida então como "influência ausente (principalmente na especialidade)". Esta categoria também foi referida "principal- 
mente" à influência sobre a escolha (ou ainda não) de uma especialidade médica, tendo sido igualmente desmembrada em:

— "sem influência e sem especialidade definida";

— "sem influência, com especialidade já definida".

Todas as categorias criadas com base nas entrevistas e seus respectivos desmembramentos encontram-se exemplificadas na Figura 2.

FigURA 2

Organograma com as categorias e subdivisões criadas com base na realização de entrevistas

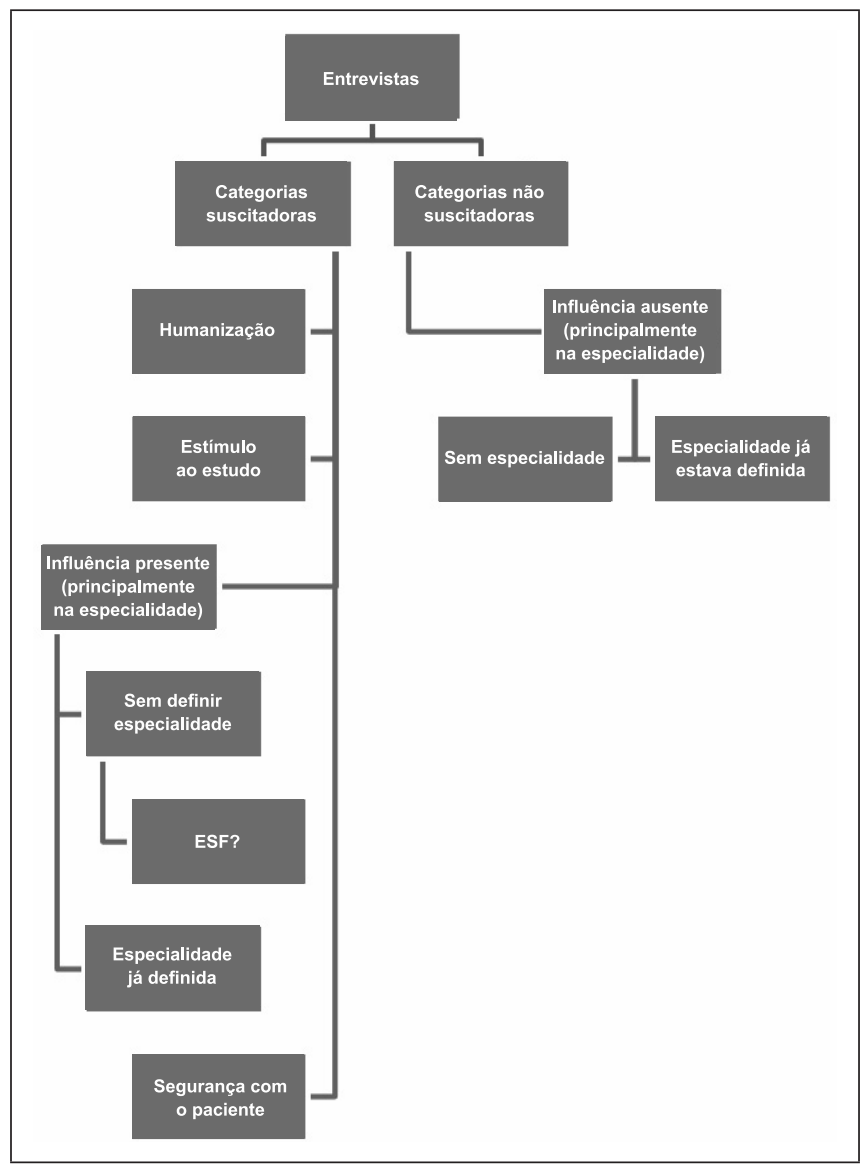

Optou-se, como já descrito, pela contagem dos enunciados ou expressões que compuseram cada categoria a fim de aferir aquela que obteve a maior frequência e, portanto, maior relevância numérica, embora esta condição não retire a importância e o significado das expressões de menor frequência. Identificou-se, então, a frequência em números absolutos frequência absoluta (FA) de cada categoria, conforme explicitado nas tabelas criadas para melhor análise comparativa, com a incorporação de frequências relativas (FR) — ou porcentagens (arredondadas) - dos estudantes que a expressaram.
Compreende-se que estes números absolutos também representam o número de entrevistados, uma vez que, pelo princípio da exclusividade na criação de categorias (Bardin, Selltiz et al. apud Gomes) ${ }^{30}$, este termo ou expressão não pode ser utilizado para "outra" categoria, representando, assim, a expressão de um único entrevistado, ou seja, cada expressão pertence efetivamente a um entrevistado. Ressalta-se que cada entrevistado pode emitir mais de uma expressão. Portanto, a soma do número de expressões não é necessariamente igual ao número total de entrevistados (no caso: 29). Da mesma forma, a soma das porcentagens destes estudantes é maior que 100\%, porque, como já explicado, há sobreposição de expressões para cada um dos estudantes.

A análise final deste trabalho considerou a categoria com a maior frequência absoluta como sendo aquela de maior significado e potencial para despertar novas reflexões ou até modificações na trajetória profissional do graduando de Medicina do Unifeso, embora não se possa desconsiderar também a importância e a significação das categorias de menor frequência absoluta na análise deste estudo.

\section{RESULTADOS E DISCUSSÃO}

A verificação da receptividade diante da transformação curricular foi um dos achados mais importantes, na medida em que $80 \%$ de "todas" as expressões contempladas neste estudo (FA total $=40$ expressões) se encontram nas categorias "suscitadoras" (FA = 32 expressões). A análise dos resultados permitiu uma interessante reflexão - e talvez a mais importante consideração realizada neste estudo - sobre a validade do estudante de Medicina ter necessariamente (ou não) realizado uma escolha (precoce) de alguma especialidade médica ou, ainda, seguir uma formação como médico generalista, conforme explicitado a seguir.

A maior parte dos entrevistados parece ser influenciada pela transformação curricular — ou seja, com a inserção na UBSF a partir do primeiro período e o uso da ABP - a ponto de haver, por exemplo, uma frequência absoluta de 16 - a maior de todas - na categoria "influência presente (principalmente na especialidade)". Nota-se que a influência da transformação curricular não traz necessariamente uma definição de especialidade, mas pode modificar uma especialidade já definida e suscitar outra em seu lugar; ou, ainda, suscitar alguma(s) sem que houvesse qualquer especialidade escolhida previamente, como se verifica nas expressões dos estudantes que se encontram na Tabela 1 .

Portanto, aparentemente para o estudante entrevistado, refletir sobre se um novo modelo curricular seria capaz de influenciar ou não sua "trajetória profissional" é quase lhe 
perguntar se ele tem ou não alguma dúvida sobre que especialidade estaria pensando em seguir, e não se sua formação como generalista - que, de fato, é como este se formará está tendo ou não alguma nova reflexão ou modificação. Este fato ocorreu para 55\% dos entrevistados classificados dentre as "categorias suscitadoras" e ainda em $28 \%$ dos entrevistados para as "categorias não suscitadoras", ou seja, 83\% (55 + 28) dos entrevistados se remeteram imediatamente à ideia da especialidade quando questionados sobre sua trajetória profissional. Em última análise, parece aqui ser quase obrigatório (re)significar o termo "trajetória profissional" como "especialização médica", ainda que estes discentes estejam sob um novo modelo curricular, como no caso analisado neste estudo.

É interessante notar que a adoção do novo modelo curricular estimula o estudo $(\mathrm{FA}=9)$, como referido nas falas: "incentiva a estudar" ou "me ensinou a buscar sempre", expressas na categoria "estímulo ao estudo", compreendida entre as "categorias suscitadoras", aspecto este fundamental e que evidencia o papel estimulador da ABP e/ou da inserção na UBSF.

Destaca-se neste estudo a categoria suscitadora humanização, que, apesar de ter apresentado o menor número absoluto $(\mathrm{FA}=6)$, representa importantes reflexões dos estudantes sobre o conceito de saúde e sobre o processo de adoecer. Esses afirmam que se sentem "mais humanizados" e que a partir desta percepção estariam repensando suas especialidades, como pode ser verificado em suas expressões na Tabela 1: "não vejo mais o paciente como doença, vejo como ser humano e percebo como somos vulneráveis".

Foi observado ainda nesta mesma categoria - humanização - que os entrevistados consideraram a condição do novo modelo curricular como suscitador de modificações de valores em sua própria vida - e não somente do ponto de vista da sua trajetória de formação profissional e especialidade médica que deverá seguir - , conforme relatado: "mudou meu olhar sobre a vida e a realidade. Não vivemos em um mundo ideal, temos que ajudar com o que podemos nos exames e nos remédios"; ou ainda, "o novo modelo exercita a visão geral e mais humanizada do paciente e isto irá marcar para sempre minha vida profissional".

Em relação às respostas e expressões apresentadas ainda na categoria suscitadora: "influência presente (principalmente na especialidade)", verificou-se que a inserção na UBSF no primeiro período e as MAEA parecem ser suficientes para "despertar" o interesse do estudante de Medicina para o cenário no qual já está inserido, conforme preconizam as $\mathrm{DCN}^{10}$. Respostas como: "queria fazer Dermatologia e agora tenho dúvidas... gostei do estilo do PSF"; "influenciou muito, se tivesse no 'tradicional' nunca pensaria em fazer PSF" ou, ainda, "a função do médico é cuidar e vi que no PSF realmente se cuida e tem uma relação mais in- tima com o paciente" parecem remeter a esta condição uma vez que estes estudantes já "pensam" na atuação em Saúde da Família. Percebe-se, portanto, que esta transformação curricular - com a inserção na UBSF e o uso da ABP — pode potencializar a possível opção pela especialidade de médico da família.

Por outro lado, ao se problematizarem as categorias suscitadoras, algumas indagações devem ser feitas, como exemplificadas na Tabela 1 :

(1) De que forma pode-se oferecer efetivamente um sentido de humanização para o estudante?

(2) O estímulo referido pela mudança curricular seria estritamente ao estudo ou existiriam outros estímulos com este novo modelo?

(3) Novas práticas significam novas especialidades ou um novo olhar sobre as especialidades já escolhidas?

(4) Há influências na sua formação como generalista?

Percebe-se que, apesar da receptividade e de novas reflexões sobre a trajetória profissional — ou especialidades — que o estudante vivencia com o novo currículo, as problematizações apontadas podem oferecer, de fato, diversos olhares ao graduando da escola médica.

Já em relação às categorias "não suscitadoras", obteve-se a $\mathrm{FA}=8$, ou seja, 20\% das expressões referidas à questão formulada sugerem que o novo modelo parece não suscitar influência na trajetória de formação profissional destes discentes, não alterando uma especialidade que já estivesse definida e, tampouco, inclinando-os a alguma especialidade, ainda que não tivessem referido alguma opção prévia. Nestas respostas foram constatadas, ainda, críticas às MAEA e às atividades na UBSF, conforme se verifica na Tabela 1 .

Já em relação à problematização apresentada para estas categorias, as indagações se tornam ainda mais importantes, como também exemplificadas na Tabela 2:

(1) Por que não estimula novas especialidades?

(2) O novo currículo possui problemas? Quais seriam?

(3) Quais são as resistências — se estas de fato existem ou há um planejamento equivocado das atividades, por exemplo, neste cenário?

(4) Que aspectos já levam o aluno a optar por uma especialidade que não seja passível de questionamento ou modificação?

Essas questões devem ser consideradas, uma vez que podem oferecer importantes reflexões para o aprimoramento curricular - tanto aos tutores envolvidos com a ABP, quanto aos preceptores dos cenários de prática - , uma vez que a existência ou não desta receptividade por parte do estudante pode estar ligada à qualidade do planejamento curricular institucional. 


\section{TABELA 1}

Relação de categorias suscitadoras criadas a partir de ideias e/ou expressões, sua frequência e referência nos estudantes e problematização correlacionada na questão: "O novo modelo curricular adotado pelo Unifeso na Faculdade de Medicina está tendo alguma influência na sua trajetória profissional?" — Teresópolis — 2008

Categorias suscitadoras e exemplos de ideias/expressões referidas

Problematização

Humanização

- “O novo modelo exercita a visão geral e mais humanizada do paciente e isto irá marcar para sempre minha vida profissional";

- "Mudou meu olhar sobre a vida e a realidade. Não vivemos em um mundo ideal, temos que ajudar com o que podemos nos exames e nos remédios";

- "A função do médico é cuidar e vi que no PSF realmente se cuida e tem uma relação mais íntima com o paciente";

- "Não vejo mais o paciente como doença, vejo o paciente como ser humano e percebo como somos vulneráveis";

- "Me aproximou mais do paciente e acho que vou ter mais facilidade com o mesmo".

De que forma se pode oferecer um sentido de humanização para o estudante?
6

21

\begin{tabular}{ll}
\hline \multicolumn{2}{c}{ Estímulo ao estudo } \\
\hline - "Estimula o estudo"; & Seria só o estímulo ao estudo ou \\
- "Corra atrás do que você quer!"; & há outros estímulos? \\
- "Me ajudará após o término da faculdade"; & \\
- "Incentiva a estudar"; & \\
- "Me ensinou a buscar sempre". & \\
\hline \multicolumn{1}{c}{ Influência presente (principalmente na especialidade) } \\
\hline
\end{tabular}

Influenciando, mas sem definição de especialidade:

- "A inserção na prática desde os primeiros períodos me possibilitou entrar em contato com diversas especialidades";

- "Me fez pensar em várias especialidades";

- "Muda muito, mas ainda não tenho definição de especialidade";

- "O cenário precoce já apura nossa visão, mas ainda não sei";

- "A abordagem prática está me auxiliando muito em relação às minhas escolhas e na minha própria habilidade";

- "Queria fazer Dermatologia e agora tenho dúvidas... gostei do estilo do PSF";

- "Influenciou e todo semestre eu mudo de especialidade porque o método te coloca frente à prática e te incita muito";

- "Influenciou muito, se tivesse no tradicional nunca pensaria em fazer PSF";

- "Verifiquei que não devo fazer uma especialidade que tenha este approach, este calor humano; quero ser mais prático".

Influenciando, mas com a especialidade já definida (modifica a maneira de ver a especialidade):

- "Influenciou, mas acho que intensificou o gosto pela Geriatria que eu já tinha";

- "Já tinha alguma inclinação para a Clínica Médica e me aguçou mais ainda";

- "Pensava na Cardiologia, mas agora com uma percepção diferente";

- "O contato precoce me fez ter mais apreço pela Psiquiatria, que já era uma especialidade pretendida".

Segurança com o paciente

- "Sinto-me mais segura com o paciente, o exame físico, por exemplo, fica mais fácil".

Por que esta segurança é mais

bem exercida no cenário de

Novas práticas significam

novas especialidades?

Há influências na sua formação

como generalista?

A prática na UBSF estimula de

fato o aluno a optar pela Saúde

da Família?

Que referenciais teórico-

16

55

práticos podem ser utilizados

neste cenário para reflexão

sobre a escolha da especialidade a seguir?

Que percepções realçam este

olhar pela especialidade prévia?

contrário, amedrontar?

Total

32

Em síntese, verificou-se que a trajetória de formação profissional do discente é influenciada pela reforma curricular do curso de graduação em Medicina do Unifeso. Oitenta por cento das expressões não só remetem a ideias de questionar, refletir, transformar ou somente endossar a especialidade médica

pretendida, como possibilitam reflexões sobre suas atitudes como futuros médicos.

As Tabelas 1 e 2 apresentam as categorias criadas e as ideias ou expressões "suscitadoras" e "não suscitadoras" correlacionadas, além da respectiva problematização sugerida 
TABELA 2

Relação da categoria não suscitadora criada a partir de ideias e/ou expressões, sua frequência e referência e problematização correlacionada nos estudantes na questão: “O novo modelo curricular adotado pelo Unifeso na Faculdade de Medicina está tendo alguma influência na sua trajetória profissional?" — Teresópolis — 2008

\begin{tabular}{ccc}
\hline $\begin{array}{c}\text { Categorias não suscitadoras e } \\
\text { exemplos de ideias/expressões referidas }\end{array}$ & Problematização & $\begin{array}{c}\text { Freq. } \\
\text { absoluta }\end{array}$ \\
& $\begin{array}{c}\text { Freq. } \\
\text { relativa (\%) }\end{array}$ \\
\hline
\end{tabular}

\section{Sem especialidade}

• "Não sei o que vou fazer e não acho que tenha influência";

- "Não sei e não influenciou";

• "Dúvidas em Neurologia e Cardiologia, mas não me senti influenciado".

\section{Especialidade já estava definida}

- "Sem influência e desde o início do curso penso na área de Ortopedia e trauma e até agora não mudei de opinião";

- “Não mudou em nada, ainda quero fazer o que já pensava, e a visão biopsicossocial vem da minha consciência e do que acredito";

- "Desde que entrei penso em fazer Cardiologia, e não me senti influenciado".
Por que não estimula novas especialidades?

O novo currículo possui problemas? Quais

seriam?

Quais são as resistências - estas de fato existem - ou há um planejamento equivocado das atividades, por exemplo, neste cenário?

Que aspectos já levam o aluno a possuir uma especialidade que não seja passível de modificação?

Total

TABELA 3

Relação entre as impressões suscitadoras e não suscitadoras referidas na questão: “O novo modelo curricular adotado pelo Unifeso na Faculdade de Medicina está tendo alguma influência na sua trajetória profissional?" — Teresópolis — 2008

\begin{tabular}{|c|c|c|c|}
\hline Questão & Expressões de possível influência & Expressões de não influência & Total \\
\hline \multirow{2}{*}{$\begin{array}{l}\text { Influência na trajetória de formação } \\
\text { profissional }\end{array}$} & Freq. absoluta $=32^{*}$ & Freq. absoluta $=8^{*}$ & 40 \\
\hline & Freq. relativa $=80 \%{ }^{* *}$ & Freq. relativa $=20 \% * *$ & $100 \%$ \\
\hline
\end{tabular}

* F.A.: Frequência Absoluta de expressões emitidas.

** Porcentagem obtida a partir da relação entre a frequência absoluta de cada uma destas expressões e o número total de expressões apuradas.

Diagrama representativo da proporcionalidade das categorias elaboradas com base nas respostas dos alunos entrevistados

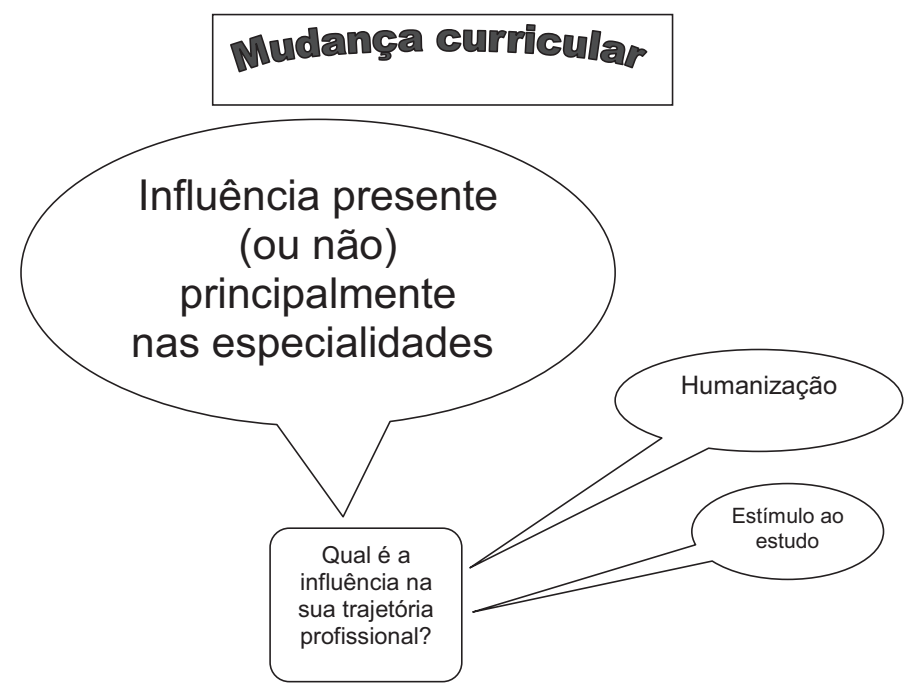


com base na questão formulada. A Tabela 3 oferece, de forma sintética, para efeito comparativo, a FA e a FR das expressões apresentadas na questão formulada pelo presente estudo. A Figura 3 representa a proporcionalidade — tamanhos dos balões - das categorias elaboradas com base nas respostas dos alunos entrevistados.

Optou-se por manter as expressões dos alunos na primeira pessoa, no intuito de preservar sua fala/expressão de modo fidedigno.

\section{CONSIDERAÇÕES FINAIS}

A investigação permitiu delimitar um contexto no qual as transformações curriculares realizadas no curso de Medicina do Unifeso - segundo as DCN e recentes programas dos ministérios da Educação e da Saúde - parecem não só suscitar reflexões sobre que novas especialidades o graduando poderá escolher ou reforçar as previamente escolhidas, mas, sobretudo, despertar referenciais que parecem essenciais na formação médica, como a humanização. Estes aspectos são fundamentais, uma vez que discutir a trajetória profissional para o estudante de Medicina parece - quase sempre - remeter à especialização, sendo esta praticamente indissociável de sua formação como médico. Em outras palavras, é como afirmar que "ser médico" é "ser um especialista". Neste sentido, compreende-se que a opção por ser um especialista é apenas a extensão da lógica reducionista que permeia o ensino médico. Portanto, torna-se possível questionar: como formar de fato generalistas em meio ao universo ainda frequentemente reducionista do ensino médico? Como produzir mudanças genuínas em meio às demandas do atual complexo médico industrial e de seus avanços tecnológicos e em meio ao reconhecimento da especialização como clímax do prestígio social e financeiro? Em relação ao SUS: qual será seu futuro se não houver um comprometimento da formação médica coerente com as suas reais e necessárias demandas sociais?

Desta forma, parece ser necessário que as escolas médicas reflitam junto aos seus alunos sobre o sentido de vocação médica, a qual é vista pelo ingressante da escola médica, inicialmente, de uma perspectiva humanitária centrada na ajuda ao próximo. A vocação, de certo modo romantizada, acaba se diluindo à medida que transcorre o curso de Medicina, transformando-se a visão humanista, pouco a pouco, em orientação para a especialidade (mais rentável), inscrita numa lógica de mercado. Nesta lógica, a escola médica não pode correr o risco de deixar de cumprir um papel fundamental — oferecer oportunidades para a formação de um generalista capaz de atuar na lógica da integralidade - , para formar pseudoespecialistas (já que formar especialistas é uma prerrogativa da residência médica). Trata-se de evitar uma ruptura nos sentidos da integralidade, uma vez que a medicina - etimologicamente ligada à física e representada como uma "ciência da natureza" - segmentar-se-ia tal qual - órgãos sem corpo ${ }^{31}$, abandonando sua acepção original e seu significado como ciência da vida ${ }^{23}$.

Neste aspecto, termos como integralidade e visão biopsicossocioambiental devem ser incorporados em toda a sua essência e considerados e entendidos como suscitadores de um novo perfil de estudante que favoreça a formação de um profissional sensível às demandas sociais e à dimensão ecológica do processo saúde-doença. A integralidade, por exemplo, deve ser compreendida como uma relação sujeito-sujeito - como se espera em díspares questões da Bioética ${ }^{32}$ - , seja nas práticas destes serviços, seja na organização dos mesmos, reconhecendo-se que tais sujeitos são portadores de desejos e de sonhos ${ }^{33}$.

Neste sentido, o PET-Saúde ${ }^{13}$ - considerado uma das estratégias do Pró-Saúde ${ }^{12}$ e que tem como fundamento a integração ensino-serviço-saúde - possui um papel de extrema relevância. Tal programa legitima os novos cenários de prática para o exercício do futuro médico, além de fomentar e prestigiar os protagonistas aí inseridos, disponibilizando bolsas para tutores, preceptores e estudantes de graduação da área da saúde. Por outro lado, o Programa de Valorização do Profissional da Atenção Básica (Provab) ${ }^{34}$ pode sensibilizar o egresso das escolas médicas para atuar como médico de família ao oferecer especialização nesta área ${ }^{34,35}$. Apoiadas por estas políticas e estratégias educacionais mais integralizadoras, as escolas médicas podem fazer jus à formação de um médico com espírito humanista e sensível às demandas sociais brasileiras na medida em que legitimem a necessária transformação curricular que deve permeá-las. Que seja o quanto antes!

\section{REFERÊNCIAS}

1. Lampert JB. Tendências de Mudança na Formação Médica no Brasil: tipologia das escolas. São Paulo: Hucitec/ ABEM; 2002.

2. Bittencourt-Costa JR, Romano VF, Costa RR, Gomes AP, Siqueira-Batista R. Active teaching-learning methodologies: medical students' views of problem-based learning. Rev Bras Educ Méd 2011;35(1):13-19.

3. Feuerwerker LCM. Além do Discurso de Mudança na Educação Médica: Processos e Resultados. São Paulo: Hucitec; 2002.

4. Siqueira-Batista R, Rôças G. Alfabetização ecológica. Rev Bras Educ Méd 2009;33(1):123-125.

5. Berlinguer G. A Doença. São Paulo: Centro Brasileiro de Estudos da Saúde; 1988. 
6. Nogueira MI. Retratos da Formação Médica nos novos cenários de prática. São Paulo: Hucitec; 2012.

7. Campos FE, Ferreira JR, Feuerwerker L, Sena RR, Campos JJB, Cordeiro H, Jr Cordoni L. Caminhos para Aproximar a Formação de Profissionais de Saúde das Necessidades da Atenção Básica. Rev Bras Educ Méd 2001; 25(2): 53-59.

8. Fiore MLM, Yazigi L. Especialidades Médicas: Estudo Psicossocial Psicologia: Reflexão e Crítica 2005; 18(2):200-206.

9. Cabral Filho WR, Ribeiro VMB. A escolha precoce da especialidade pelo estudante de medicina: um desafio para a Educação Médica Rev.bras. educ. méd; 2004; 28(2): 133-144.

10. Brasil. Ministério da Educação. Conselho Nacional de Educação. Câmara de Educação Superior. Resolução CNE/CES n. 4, de 7 de novembro de 2001. Institui Diretrizes Curriculares Nacionais do Curso de Graduação em Medicina. Diário Oficial da União, Brasília, 9 de novembro de 2001. Seção 1, p. 38.

11. Brasil. Ministério da Saúde. Ministério da Educação. Organização Panamericana da Saúde. Programa de Incentivo a Mudanças Curriculares nos Cursos de Medicina. Brasília: Secretaria de Políticas da Saúde; 2002. [Edital de Convocação].

12. Brasil. Ministério da Saúde. Ministério da Educação. Programa Nacional de Reorientação da Formação Profissional em Saúde. PRÓ-SAÚDE: objetivos, implementação e desenvolvimento potencial. Brasília: Ministério da Saúde, Ministério da Educação; 2007. 86p.

13. Brasil. Ministério da Saúde. Ministério da Educação Gabinete do Ministro. Portaria Interministerial no 421, de 03 de Março de 2010. Institui o Programa de Educação pelo Trabalho para a Saúde PET-Saúde. Diário Oficial da União n 43, Brasília, 05 de Março de 2010. Seção 1; p. 52.

14. Campos GWS. Papel da Rede de Atenção Básica em Saúde na Formação Médica - Diretrizes. Documento preliminar. [Acesso 10 jan 2008]. Disponível em: <www.abem. educmed.org.br: pdf:doc-prof-gastão.pdf $>$.

15. Ferreira RC, Silva RF, Agner CB. Formação do Profissional Médico: a Aprendizagem na Atenção Básica de Saúde. Rev Bras Educ Med 2007; 31(1):52-59.

16. Andrade LOM, Barreto ICHC, Fonseca CD, Harzheim E. A Estratégia de Saúde da Família. In: Duncan BB, org. Medicina ambulatorial. Condutas de atenção primária baseadas em evidências. Porto Alegre: Artmed; 2006. p.88-100.

17. Gomes AP, Rego S. Transformação da educação médica: é possível formar um novo médico a partir de mudanças no método de ensino-aprendizagem? Rev Bras Edu Med 2011; 35(4):557-566.

18. Siqueira-Batista R, Batista RS. Os anéis da serpente: a aprendizagem baseada em problemas e as sociedades de controle. Ciên Saúde Col 2009; 14:1183-1192.

19. Toralles-Pereira ML, Cyrino EG. Trabalhando com estratégias de ensino-aprendizado por descoberta na área da saúde: a problematização e a aprendizagem baseada em problemas Cadernos de Saúde Pública 2004; 20(3):780-788.

20. Vasconcelos EM, Frota LH, Simon E. Perplexidade na Universidade vivências nos cursos de saúde. São Paulo: Hucitec; 2006.

21. Fleuri RM. Formação de profissionais da saúde Reflexões a partir de vivências estudantis. In: Vasconcelos EM, Frota LH, Simon E. Perplexidade na Universidade vivências nos cursos de saúde São Paulo: Hucitec; 2006. p. 231-264.

22. Cotta RMM, Gomes AP, Maia TM, Magalhães KA, Marques ES, Siqueira-Batista R. Pobreza, injustiça, e desigualdade social: repensando a formação de profissionais de saúde. Rev Bras Edu Med 2007; 31(3):278-286.

23. Portocarrero V. As Ciências da vida de Canguilhem a Foucault. Rio de Janeiro: FIOCRUZ; 2009.

24. Fundação Educacional Serra dos Órgãos. O Projeto de Mudança Curricular do Curso de Medicina da FESO. Teresópolis; 2004. Mimeo.

25. Projeto Político-Pedagógico Institucional do Centro Universitário Serra dos Órgãos. Teresópolis: UNIFESO; 2006.

26. Minayo MCS. O Desafio do Conhecimento - Pesquisa qualitativa em saúde. 6. ed. São Paulo; Rio de Janeiro: HUCITEC-ABRASCO; 1999.

27. Fontanella BJB, Ricas J, Turato ER. Amostragem por saturação em pesquisas qualitativas em saúde: contribuições teóricas. Cad. Saúde Pública 2011; 24(1):17-27.

28. Brasil. Resolução 196/96. Conselho Nacional de Diretrizes e Saúde. Normas regulamentadoras das pesquisas envolvendo seres humanos. [Acessado em 07 fev 2012]. Disponível em: http:/ / www.ufrgs.br/bioética/res.19696.htm

29. Bardin L. Análise de Conteúdo. 3 ed. Lisboa: Edições 70; 2004.

30. Gomes R. A análise de dados em pesquisa qualitativa. In: Minayo MCS, Deslandes SF, Neto OC, Gomes R. Pesquisa Social - Teoria, método e criatividade. Petrópolis: Vozes; 1994; 67-80.

31. Siqueira-Batista R. O cuidado integral em questão: diálogos entre filosofia e medicina (Editorial). Brasília Médica 2010; 47:273-275.

32. Siqueira-Batista R, Schramm FR. A bioética da proteção e a compaixão laica: o debate moral sobre a eutanásia. Ciên Saúde Col 2009; 14:1241-1250. 
33. Mattos RA. Os sentidos da Integralidade: algumas reflexões acerca de valores que merecem ser definidos. In: Pinheiro R; Mattos RA. Os Sentidos da Integralidade na atenção e no cuidado à saúde. Rio de Janeiro: IMS/UERJ/ ABRASCO; 2001; p.39-64

34. Programa de Valorização do Profissional da Atenção Básica. [Acesso em 10 jan 2013]. Disponível em: vhttp:// portal.saude.gov.br/portal/saude/profissional/area. cfm?id_area=1855.

35. Gomes AP, Bittencourt-Costa JR, Junqueira TS, Arcuri NB, Siqueira-Batista R. et al. Atenção primária à saúde e formação médica: entre episteme e práxis. Rev Bras Educ Med 2012; 36:541-549.

\section{CONTRIBUIÇÃO DOS AUTORES}

O estudo foi desenhado por José Roberto Bittencourt Costa, sob a orientação de Luiz Anastácio Alves. José Roberto Bitten- court Costa e Rosane Rodrigues Costa participaram da coleta de dados e da primeira elaboração do texto. A versão final do texto e a discussão final dos dados foram feitas por Valéria Ferreira Romano, Andréia Patrícia Gomes, Rodrigo Siqueira-Batista e Luiz Anastácio Alves.

\section{CONFLITO DE INTERESSES}

Não há conflito de interesses.

\section{ENDEREÇO PARA CORRESPONDÊNCIA}

José Roberto Bittencourt Costa

Coordenação de Medicina

Centro Universitário Serra dos Órgãos - UNIFESO

Av. Alberto Torres, 111 Alto - Teresópolis

CEP: 25964-004 RJ

E-mail: joserobertobcosta@unifeso.edu.br 